\title{
Gauging the Effects of Potential Chemical Transferal on High Flood-Risk Fenceline Communities
}

\author{
G. Newman ${ }^{1 *}$, Z. Cai ${ }^{1}$, R. Zhu ${ }^{1}$, J. A. Horney ${ }^{2}$, S. Jang ${ }^{3}$, and W. A. Chiu ${ }^{3}$ \\ ${ }^{1}$ Department of Landscape Architecture and Urban Planning, Texas A\&M University, College Station, TX, 77843 USA \\ ${ }^{2}$ Department of Epidemiology, University of Delaware, Newark, DE, 19713 USA \\ ${ }^{3}$ Department of Veterinary Integrative Biosciences, Texas A\&M University, College Station, College Station, TX, 77843-4458 USA
}

Received 05 August 2021; revised 26 September 2021; accepted 27 October 2021; published online 06 November 2021

\begin{abstract}
Hurricane Harvey demonstrated how natural disasters and changing environmental conditions can substantially increase pollutant releases from industrial facilities. Releases from such facilities in already flood- and pollution-vulnerable communities will further exacerbate existing negative public health outcomes. In this study, we focus on the TX neighborhood of Galena Park, a socially vulnerable, fenceline community in the Greater Houston Area that suffers from frequent flooding and environmental justice issues, as well as being the location of the largest reported chemical spill after Hurricane Harvey in 2017. To help improve the resilience of this community to hurricane/flood-induced releases of contaminants, we analyzed geospatial data on flood risk related to storm surge as well as the current and future 100-year flood plain using advanced ArcGIS Dashboard operations. We then linked these flood risks to vulnerabilities to flood-induced contamination releases through proximity to environmentally regulated facilities.
\end{abstract}

Keywords: contamination, environmental justice, environmental performance, flood resilience, geographic information systems, urban analytics

\section{Introduction}

The convergence of flood disasters and environmental contamination heightens the potential for mobility and transfer of toxic substances (Newman et al., 2020). These risks are particularly impactful for what are referred to as fenceline communities - neighborhoods that are immediately adjacent to a company or industry and are directly affected by the noise, odors, chemical emissions, traffic, parking, and/or operations of said company/industry (Johnston and Cushing, 2020). Galena Park, TX, USA is one such community experiencing multihazard risks of both flooding and chemical exposure. The chemical releases reported in the U.S. Environmental Protection Agency (EPA) (2019) Toxics Release Inventory (TRI) and the State of Texas Environmental Electronic Reporting System identify twelve major industrial complexes (including multiple facilities within these complexes) in Galena Park, TX, USA, that have the potential for additional releases as a result of flooding/hurricanes. These facilities represent a range of industries, from petroleum, to chemicals, to building materials. Additionally, five of these twelve complexes have registered EPA Risk Management Plans (2019), indicating that they use large amounts of extremely hazardous chemicals and/or have

" Corresponding author. Tel.: +1 979-862-4320.

E-mail address: gnewman@arch.tamu.edu (G. Newman).

ISSN: 2663-6859 print/2663-6867 online

(c) 2021 ISEIS All rights reserved. doi:10.3808/jeil.202100073 had serious accidents or releases. For example, the Magellan Marine Terminal is particularly noteworthy, as following Hurricane Harvey damage to this facility there were extremely large releases of fuel and associated volatile organic compounds (VOCs) into the Galena Park community (Texas Commission on Environmental Quality, 2017).

A growing body of research has demonstrated that both natural (Bolin and Kurtz, 2018) and technological (Cope et al., 2017) disasters have disproportionate impacts on socially vulnerable communities (Flanagan et al., 2018). In socially vulnerable communities - those with a high proportion of low income and majority-minority households - residents live disproportionately in close proximity to polluting industrial facilities and in areas at higher risk from the impacts of hurricanes, floods, and other hydrometeorological disasters (Bullard, 2007; Collins et al., 2016). In these settings, the potential for a release of hazardous materials with human health impacts associated with direct (e.g., flooding) or indirect (e.g., explosions, fires) impacts of disasters is increased (Summers et al., 2021). Between 1990 and 2010, there were approximately 17,000 toxic material releases caused by natural disasters; $46 \%$ resulting from flooding and hurricanes (Sengul et al., 2012). Low-income and minority residents make up a larger proportion of individuals living near these sites and are therefore most vulnerable (Carter and Kalman, 2019).

More recently, attention has been increasingly focused on the public health and other risks associated with the convergence of these exposures as contaminants from Superfund sites, 
TRI facilities, and other industrial sites are mobilized by floods (Bodenreider et al., 2019; Newman et al., 2021). For example, designated Superfund sites in Houston, Texas are designated as "highly vulnerable" to inland flooding, as well as highly likely to experience multi-hazard exposure (Summers et al., 2021). Going forward, climate change, sea-level rise, urbanization and reduction of pervious surfaces, subsidence, saltwater intrusion and other factors are also interacting to increase these risks, particularly in places like the U.S. Gulf Coast (Brody et al., 2014; Miller and Shirzaei, 2019, 2021). By 2041, 34\% more contaminated urban sites and $61 \%$ more U.S. Census tracts are predicted to be at high risk for the dispersion of toxins due to flooding (Marcantonio et al., 2019).

After Hurricane Harvey impacted the Houston, Texas region, there was widespread evidence of this convergence of risk. The extent of flooding was spatially correlated with the proportion of residents who were Hispanic or non-Hispanic Black and the proportion designated as living in socioeconomic deprivation (Chakraborty et al., 2019). Simultaneously, petrochemical releases were more likely in U.S. Census tracts with a higher proportion of Hispanic residents, as well as in communities with more residents who were disabled or living in poverty (Flores et al., 2021). Higher concentrations of polycyclic aromatic hydrocarbons were found after Hurricane Harvey in a low-lying environmental justice neighborhood, where floodwaters from the storm accumulateed (Stone et al., 2019), while the extent of flooding within 100 meters of a residence was significantly greater for households that were low income and racial or ethnic minorities (Collins et al., 2019). This increased, and the growing potential for synergistic impacts from the dual exposure to natural hazards and chemical and other types of contaminant exposures necessitates the development of new tools to assist planners, regulators, and residents with risk assessment and risk communication.

Capabilities for visualizing and modeling interactions between flood events and hazardous substance exposure to expose risk have been relatively unachievable until the recent decade; articles lining the subject matter have also been rare (Psyllidis et al., 2015). Traditionally, because cities are complex by nature, computer visualizations will involve synthesizing a variety of complex physical and non-physical digital tasks and algorithms (Newman et al., 2020). Newer, more automated and userfriendly approaches to data visualization and urban analytics have surfaced as a result of deeper understandings of computer science. For example, online platforms such as Geographical Information Systems (GIS) Dashboards now allow the capabilities to present, assess, and interpret location-based analytics using intuitive and interactive data visualizations. Probably, the most famous current example is the Center for Systems Science and Engineering's COVID-19 ArcGIS Dashboard from John Hopkins University, a dynamic data display mechanism measuring and displaying COVID-19 cases globally.

ArcGIS Dashboards can display key performance indicator information for research projects in easy-to-read gauges and charts alongside spatially referenced mappings to visualize and understand the impacts of built environment conditions (Molefi et al., 2020). Such platforms can visualize trends, monitor sta- tus in real time, and inform communities to help them make decisions (Lee et al. 2018). Capabilities to transfer data outputs as inputs to new platforms would better allow the convergence of information and dissemination of more accurate results while simultaneously allowing for more complex analyses and methodologies. Increasingly pervasive digital information is transforming research product delivery models. To better streamline the research process, digital urban analytics platforms need to consistently adapt to ongoing digital change. To enable this, new directions to extend the understanding of digitally enabled integrated platforms and solutions are necessary (Whyte, 2019).

ArcGIS Dashboards afford the possibility to display data linked to key performance indicators for specific research topics with built-in, easy-to-read gauges and charts. Such inherit analytics are linked to geo-spatially referenced mappings and can be used to help understand the effects of circumstances related to build environment conditions through advanced and customizable visualizing techniques. Online platforms such as ArcGIS Dashboards provide the capability to present, assess, and interpret location-based analytics using intuitive and interactive data visualizations, which can help elucidate conditions related to multi-hazard exposures. Such findings can assist in developing research questions, selecting research methods, and visualizing data to use in engagement processes with communities for disseminating information through research translation. Such capabilities allow to both visualize and evaluate multi-hazard exposures, which is particularly beneficial to fenceline communities who are prone to experience a myriad of negative hazard conditions. Based on these findings, this research advances this current body of literature by using advanced urban analytical and visualization tools to determine the current and future risks of contaminant transferal during different flood events (including future sea level rise) in an underserved, largely minority community. The innovation in this research lies in 1) it inspirates sea level rise projections using NOAA data into the 100-year floodplain area change analytics when most research only uses the basic projected water level change, 2) our visualization technique utilizes scale differentiation incurporating the entire city as well as breakdowns at the census block scale, and 3) this is the first Dashboard, to our knowledge, that incorporates Risk-Screening Environmental Indicators (RSEI) scores into the flood scenario visualization and analytical methods as a way to measure contaminant load. Using an ArcGIS Dashboard, this research asks, what are the current risks of contaminant transferal during flood events in Galena Park, TX, and how will these risks be altered with climate change-related sea level rise?

To help answer this question, methodologically, we used data provided by the Coastal Risk Screening Tool which describes and projected to be below the annual flood level by 2100 developed by Climate Central to obtain the area of the predicted 100-year floodplain. The Coastal Risk Screening Tool enables users to explore sea level rise and coastal flood risk over time, for anywhere in the world, and under multiple pollution scenarios. The tool allows users to choose to incorporate the most accurate elevation data available not Climate Central's sea level rise models. The platform maps sea level rise and coastal flood 
risk using scientifically rigorous information that Climate Central and displays it within an easy-to-use online interface. The Coastal Risk Screening Tool links to Climate Central's global mapping interface, allowing stakeholders to explore various sea level rise and coastal flood risk scenarios. Through the tool, we were able to obtain the predicted water level change of 2040 , 2060, 2080 and 2100 in top-view by downloading the area in PNG format. We then imported the Water Level PNGs into AutoCAD to manually delineate the areas and saved them as dwg. Files. After, we imported the dwg. files into ArcGIS Pro and created polygon shapefiles for them using NAD 1983 State Plane Texas S Central FIPS 4204 (US Feet) as the coordinate system. Finally, in the attribute table for the water levels of 2040, 2060, 2080, and 2100, we included the information of ID, Shape, Water Level, Year, and Area for each shapefile.

\section{Methods}

\subsection{Study Area}

Galena Park is a 5712-acre city in Harris County, Texas, tangential to the eastern edge of the City of Houston. Flooding regularly impacts it from Buffalo Bayou and multiple industrial land uses are located to the south (see Figure 1). Due to its flat topography and adjacence to Buffalo Bayou, the city is at high risk of inundation and flooding from stormwater, surge, and riverine overtopping. In fact, nearly 500 acres $(\sim 9 \%)$ of the total study area is within the 100-year flood plain; this percentage is expected to increase with sea-level rise and worsen even more when considering the storm surge flood plain.

\subsection{Data Preparation}

To examine how mixtures of contamination due to sources contributing to hazardous substance could be potentially affected by hurricanes (Wilson, 2014) or riverine-based flooding (Grineski et al., 2015), we applied three categorizations to the data. First, inundated land area as a result of storm surge events including categories 1 through 5 was used as a classification (Zachry et al., 2015). These data were downloaded from the National Hurricane Center and Central Pacific Hurricane Center (https://www.nhc.noaa.gov/nationalsurge/) in a GeoTIFF format. Such data are retrieved as 8-bit unsigned integer raster datasets corresponding to $1 \mathrm{ft}$ inundation bins. Further, the storm surge dataset both visualizes and assesses inundated area by showing storm surge height across all five hurricane categories on a mapped surface. The heights include the following information per surge category: Category 1 ( 0 to $6 \mathrm{ft}$ above the ground), Category 2 ( 0 to $12 \mathrm{ft}$ above the ground), Category 3 ( 0 to $18 \mathrm{ft}$ above the ground), Category 4 ( 0 to $20 \mathrm{ft}$ and greater than $20 \mathrm{ft}$ above the ground), and Category 5 ( 0 to $20 \mathrm{ft}$ and greater than $20 \mathrm{ft}$ above the ground). The second categorization utilized the current and predicted 100-year floodplain with sea level rise by the current year, 2040, 2060, 2080 and 2100. These data incorporated the levels of sea level rise with major flood projection type and unchecked pollutant loads. As a side note, the data can be only downloaded as a PNG from the website for common user. The authors, therefore, had then digitized within in Arc-
GIS Pro into a shapefile format geocoded based on longitude and altitude coordinates. Finally, we applied the categorization of Galena Park potential contamination sources. These data including the results of the EPA's RSEI scores (calculated as toxicity weight multiplied by the exposed population, then multiplied by the estimated dose) as well as information from the Texas Commission on Environmental Quality (TCEQ) distinguishing location of regulated facilities (including name, address, primary business, program, ID type/ number and ID status) and locations of TRI-reporting facilities (Kanashiro, 2020).

These data were imported into Map Viewer for visualization and analysis within an ArcGIS Dashboard (See Table 1). For the storm surge data, each dataset was initially in raster format and was converted into shapefiles in ArcGIS Pro (AGP) and then shared as web layers within the ArcGIS Online Portal. For existing and predicted 100-year floodplain with sea level rise, we created shapefiles for the 100-year floodplain of 2040, 2060, 2080, and 2100 by delineating downloaded PNGs in AGP and geolocated them manually. After transforming them into shapefiles, we also shared these data as web layers into the ArcGIS Online Portal. For the Galena Park potential contamination sources, we reclassified the RSEI scores proportionally on the map and imported the TCEQ facilities and TRI-reporting facilities in AGP according to their latitude and longitude. After attaching all necessary information in the attribute tables for them, we also shared as web layers within the ArcGIS Online Portal.

Table 1. Datasets Utilized to Create the Dashboard

\begin{tabular}{llll}
\hline Category & Description & Source & Year \\
\hline Storm Surge & Categories 1 to 5 & $\begin{array}{l}\text { National Storm } \\
\text { Surge Hazard } \\
\text { Maps - Version 2 }\end{array}$ & \\
Predicted 100- & $\begin{array}{l}\text { Land projected to be } \\
\text { below 100-year flood } \\
\text { level, together with sea- }\end{array}$ & $\begin{array}{l}\text { Climate Central - } \\
\text { Coastal Risk } \\
\text { Sear }\end{array}$ & \\
Floodplain & Screening Tool & \\
& $\begin{array}{l}\text { level rise and pollutant } \\
\text { amounts }\end{array}$ & \\
Pollutant & $\begin{array}{l}\text { Locations of TCEQ- } \\
\text { regulated facilities, TRI- }\end{array}$ & EPA \\
Estimation & $\begin{array}{l}\text { reporting facilities, and } \\
\text { EPA's RSEI scores }\end{array}$ & & \\
\hline
\end{tabular}

\subsection{Data Processing}

From data preparation to ArcGIS Dashboard visualization, interactions are required among four platforms: AGP, ArcGIS Online Portal, Map Viewer, and the actual Dashboards (See Figure 2). In AGP, we selected each shapefile layer and shared it as a web layer to publish it into the ArcGIS Online Portal. Then, we opened each layer in Map Viewer from ArcGIS Online Portal and altered the legends, appearance, or added more layers as needed. After saving the edited map from the Map Viewer, we created a blank Dashboard and saved the maps into it. In the Dashboards program, we then added several charts, indicators, gauges, and other text information based on layer attributes related to the research question. 


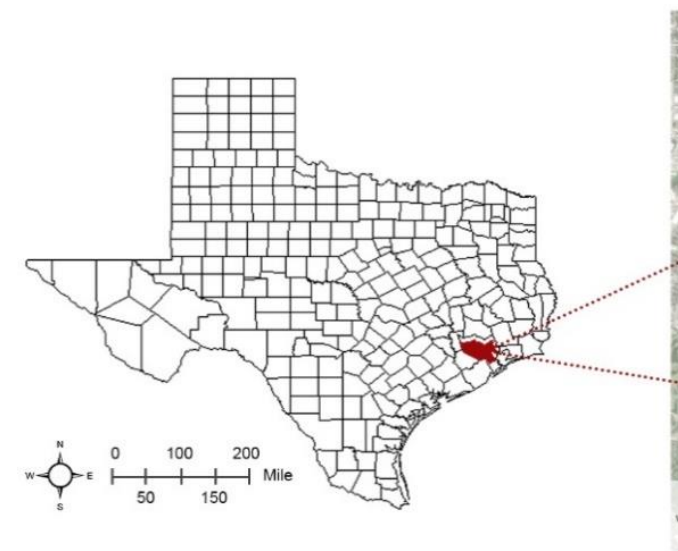

\section{Texas County Map}

Highlight area is Harris County, and the Galena Park locates in its eastern part.

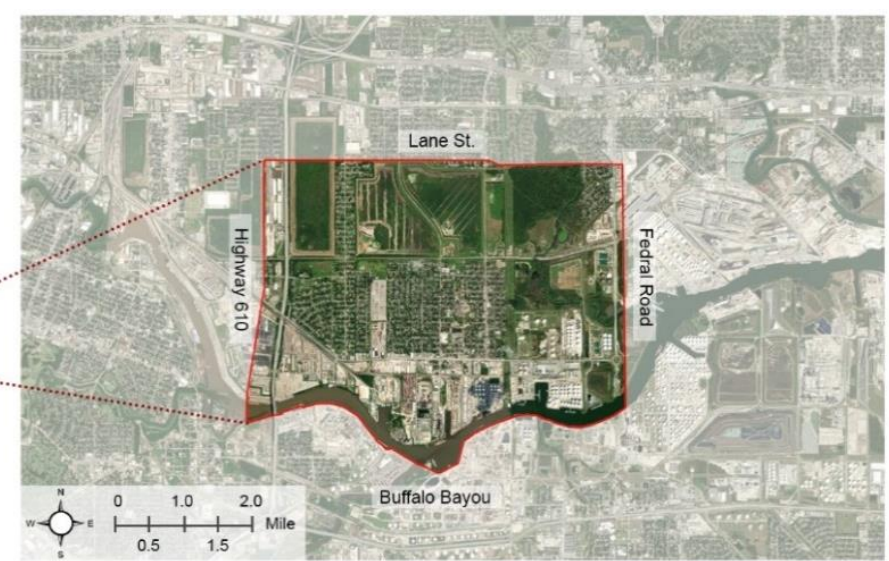

Study Area in Galena Park

Study area is about 5712 acres, and $8.7 \%$ of it is waterbody (498 acres).

Figure 1. Study Area Diagram Showing Location of Galena Park, TX.

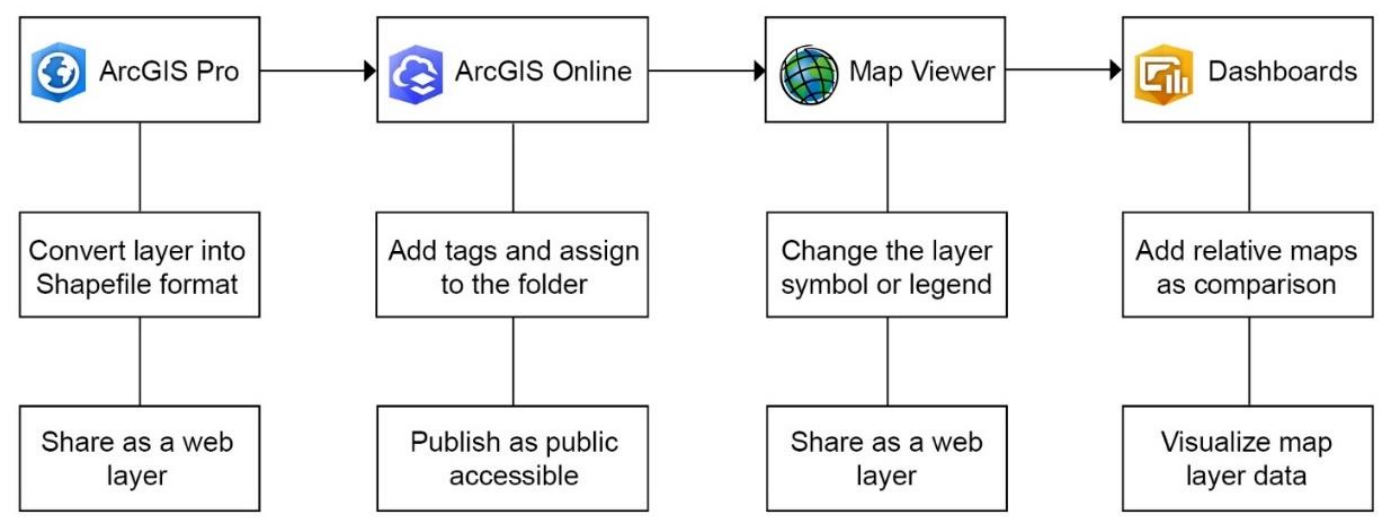

Figure 2. Workflow of Data Processing.

\subsection{Data Analysis}

To analyze the results from the Dashboard, we assess the data from two perspectives, storm surge and the current and predicted 100-year floodplain with sea level rise. Simultaneously, each map is evaluated according to three criteria: 1) total inundated area, 2) total number of TCEQ-regulated facilities inundated, and 3) the total amount of RSEI Scores within the inundated area.

\section{Results}

\subsection{Vulnerabilities due to Storm Surge}

Compared with the threat from 100-year floods, even with sea level rise, storm surge projects to have a much more severe impact on contamination releases during flood events within the study area. While images for each of the following calculations are not shown in this article, readers can interact and view them on the dashboard here: https://tamu.maps.arcgis.com/ apps/dashboards/61f6b533aebd4db381a062f8402ccb76. From Categories 1 through 5 storm surge, the percentage of inundat- ed area corresponds to $0.8 \%$ (Category, 1: 45 acres), $2.4 \%$ (Category 2: 136 acres), 10.0\% (Category 3: 570 acres), 27.5\% (Category 4: 1,568 acres) and 42.6\% (Category 5: 2,433 acres), respectively. Notably, a Category 5 storm surge will inundate over half of the study area, nearly 45 times greater than a Category 1 storm surge. A Category 4 storm surge will impact the study area dramatically compared with a Category 3 surge, encompassing nearly three times as much inundated area.

There are 213 TCEQ-regulated facilities within the study area that have the potential to be flooded. The Category 5 storm surge, having the greatest threat, will flood approximately three times more TCEQ facilities than that of a Category 3 surge. Specifically, 20.2\% (43 sites) of the TCEQ facilities will be inundated by a Category 3 storm surge, $56.8 \%$ (121 sites) by a Category 4 surge and $71.4 \%$ (152 sites) in a Category 5.

With respect to EPA's RSEI scores, RSEI totals for Categories 4 and 5 surges double those of Categories 2 or 3, indicating a much greater pollutant threat and hazardous substance mixture potential to residents. Specifically, in surge Categories 4 and 5, the RSEI scores reach 153,878 and 154,287 respectively, with an RSEI total of 73,462 in both Categories 2 and 3. 

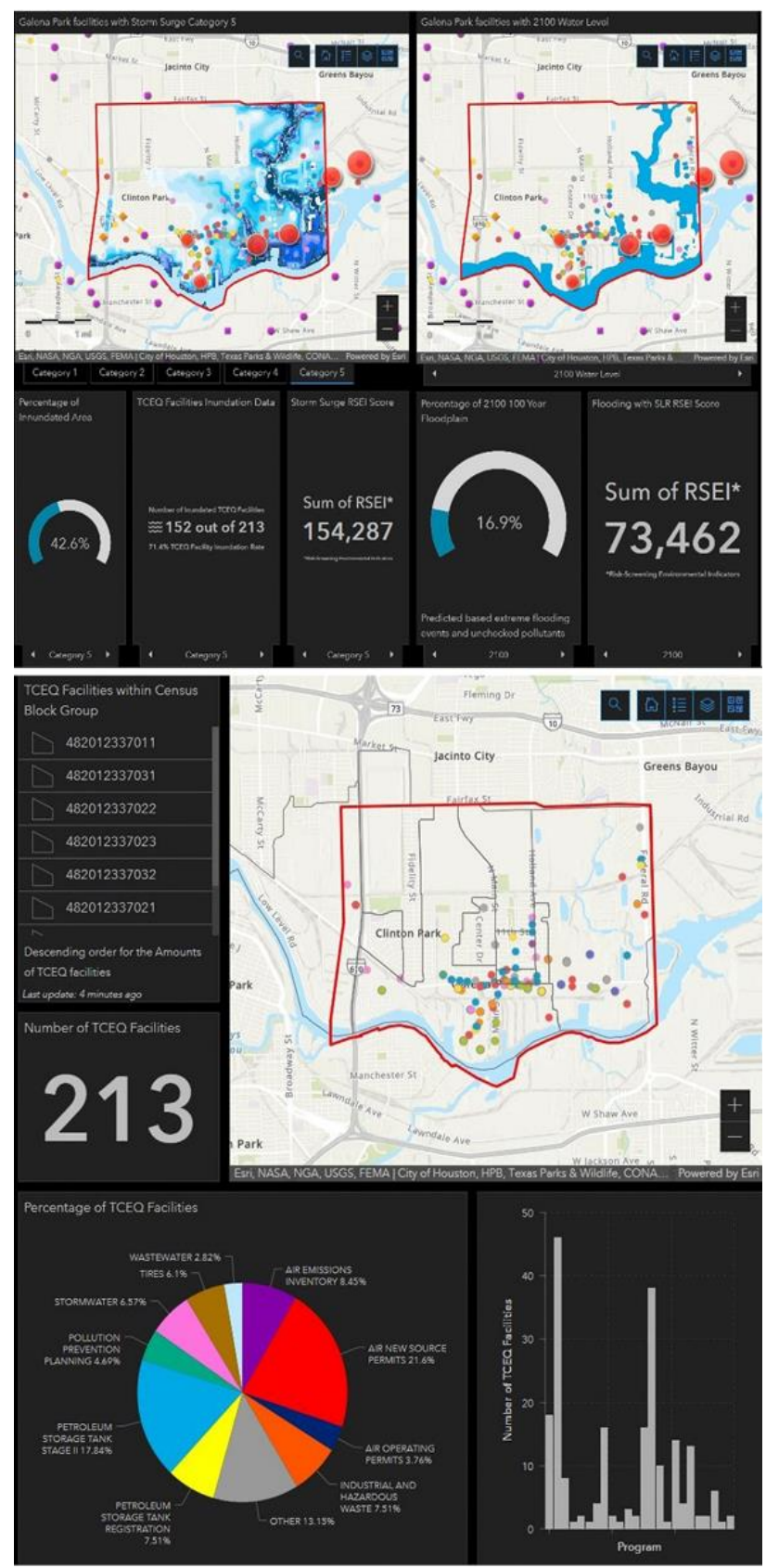

Figure 3. Full Dashboard Showing Surge, 100-Year Floodplain and Projections, and Contamination (top), as well as Breakdowns by Census Block Group (bottom) in Galena Park, TX.

\subsection{Vulnerabilities due to Expanded 100-Year Floodplain}

Compared with the storm surge, flooding within the 100year flood plain, even with sea level rise projections built in, has a smaller impact on the study area compared to examining the same aspects evaluated by storm surge. There will be no TCEQ facilities inundated within the political boundaries of Galena Park under all 100-year floodplain scenarios. However, with respect to the EPA's RSEI scores, while there projects to be minimal inundation currently and within the 2040, 2060, and 2080 scenarios, the 100-year floodplain by 2100 increases the risk of contaminant mixtures and their impacts on the local population, showing a score of 73,462 . In fact, the 100 -year floodplain by 2100 projects to nearly double the area of the current 100-year floodplain. Specifically, the current flood plain covers 498 acres (8.7\%), and those of 2040, 2060, 2080, and 2100 will range from 635 acres $(11.1 \%), 750$ acres $(13.1 \%)$, 829 acres $(14.5 \%)$ and 964 acres $(16.9 \%)$, respectively.

\subsection{Impacts by Block Group}

Utilizing the census block group as the unit, we then used the Dashboards to rank each block group within Galena Park by risk level to summarize 1) the amounts of TCEQ facilities and 2) the area of storm surge and floodplain in each census block group (See Figure 3). When examining TCEQ facilities using the census block group unit of analysis, we found that 8 out of 10 census block groups have TCEQ facilities within the neighborhood. In particular, one census block group (482012337011) comprises approximately half of the total TCEQ facilities, (124 out of 213). Further, one-third of all of the TCEQ facilities in Galena Park is labeled as Air New Source Permit facilities. Detailed statistics of each census block group with Galena Park are displayed in Table 2, including the name of the census block group, amounts of TCEQ facilities, and the major TCEQ program.

\section{Conclusions}

This research used ArcGIS Dashboards to examine multihazard risk exposures in a fenceline community to assess both the current risks of contaminant transferal during flood events in Galena Park, as well as how such risks would change due to anticipated sea level rise. We find that, while short-term sealevel rise will not significantly impact the current conditions, long-term sea-level rise will moderately increase contaminant exposures during flood events. By contrast, existing and future storm surge events pose an immediate and dire risk to the spreading and mixing of pollutant loads. Moreover, the 100year floodplain expansion due to sea-level rise by 2100 increases the risk of contaminant mixtures, according to the EPA's RSEI scores. Furthermore, even within Galena Park, there is a high degree of geographical heterogeneity. For instance, while $80 \%$ of census block groups include TCEQ facilities within the neighborhood, reflecting severe environmental inequality problems, almost half of the facilities are within a single block group.

Many fenceline communities such as Galena Park suffer from environmental inequities due to their proximity to industrial land uses that emit hazardous substances (Bullard, 2005). ArcGIS Dashboards can be a vital tool to integrate inventories and mappings of existing conditions, data analytics, and visualizations of data with geography. Such an integration can inform planners, policymakers, and the public about environmental inequality issues so that more emphasis can be placed on how to control flooding and pollutant loads in fenceline communities. 
Table 2. Data Summary for Storm Surge, Water Level and TCEQ in Census Block Group

\begin{tabular}{|c|c|c|c|c|c|c|c|c|c|c|c|c|}
\hline \multirow{2}{*}{$\begin{array}{l}\text { Census Block } \\
\text { Group GEOID }\end{array}$} & \multicolumn{5}{|c|}{ Storm Surge Affected Area (Acres) } & \multicolumn{5}{|c|}{ Floodplain Affected Area (Acres) } & \multirow{2}{*}{$\begin{array}{l}\text { No. of } \\
\text { TCEQ }\end{array}$} & \multirow{2}{*}{$\begin{array}{l}\text { Major TCEQ } \\
\text { Program }\end{array}$} \\
\hline & Category & 1Category & Category & 3 Category & 4 Category & 5 Current & 2040 & 2060 & 2080 & 2100 & & \\
\hline 482012337011 & 19.36 & 56.13 & 191.90 & 505.24 & 761.18 & 257.28 & 309.42 & 328.39 & 333.40 & 358.85 & 124 & $\begin{array}{l}\text { Air New Source } \\
\text { Permit }\end{array}$ \\
\hline 482012337031 & 24.22 & 67.75 & 327.76 & 788.60 & 979.72 & 214.92 & 296.00 & 385.42 & 453.14 & 558.64 & 52 & $\begin{array}{l}\text { Air New Source } \\
\text { Permit }\end{array}$ \\
\hline 482012337022 & - & - & - & 16.27 & 42.39 & - & - & - & - & - & 13 & $\begin{array}{l}\text { Petroleum } \\
\text { Storage Tank } \\
\text { Stage II }\end{array}$ \\
\hline 482012337032 & - & 4.92 & 19.74 & 89.36 & 121.86 & 1.24 & 3.05 & 7.32 & 12.41 & 13.29 & 9 & $\begin{array}{l}\text { Petroleum } \\
\text { Storage Tank } \\
\text { Stage II }\end{array}$ \\
\hline 482012337023 & - & - & 10.15 & 67.91 & 227.24 & 0.10 & 0.10 & 0.10 & 1.28 & 3.18 & 5 & $\begin{array}{l}\text { Petroleum } \\
\text { Storage Tank } \\
\text { Stage II }\end{array}$ \\
\hline 482012125003 & 1.42 & 7.20 & 20.45 & 32.95 & 42.32 & 24.46 & 26.43 & 28.77 & 28.77 & 30.04 & 4 & $\begin{array}{l}\text { Petroleum } \\
\text { Storage Tank } \\
\text { Stage II }\end{array}$ \\
\hline 482012337021 & - & - & - & 51.89 & 116.07 & - & - & - & - & - & 2 & $\begin{array}{l}\text { Petroleum } \\
\text { Storage Tank } \\
\text { Stage II }\end{array}$ \\
\hline 482012337012 & - & - & - & 15.78 & 142.22 & - & - & - & - & - & 2 & Tires \\
\hline Total & 45.00 & 136.00 & 570.00 & 1568.00 & 2433.00 & 498.00 & 635.00 & 750.00 & 829.00 & 964.00 & 211 & N/A \\
\hline Percentage & $0.8 \%$ & $2.4 \%$ & $10.0 \%$ & $27.5 \%$ & $42.6 \%$ & $8.7 \%$ & $11.1 \%$ & $13.1 \%$ & $14.5 \%$ & $16.9 \%$ & N/A & N/A \\
\hline
\end{tabular}

To better cope with the pollutant spread and mixture due to storm surge and flood events, both engineered and nature-based solutions can be employed to block both water and the spread of contaminants (Bernier et al., 2018). Further, evacuation planning and preparation for pollution accidents also need to take special considerations for fenceline communities, which are more likely to be affected (Saha et al., 2018). More research is necessary to link additional digital data sources and related analytics to visualize flood risk zones and identify vulnerable places before flooding occurs, so as to help develop better plans to prevent or mitigate the impacts of floods.

Acknowledgments. This work was supported, in part, by the National Institutes of Health (P42 ES027704) and the U.S. Environmental Protection Agency (STAR RD84004601). The views expressed in this manuscript do not reflect those of the funding agencies. The use of specific commercial products in this work does not constitute endorsement by the authors or the funding agencies.

\section{References}

Bernier, C., Kameshwar, S., Elliott, J.R., Padgett, J.E. and Bedient, P.B. (2018). Mitigation strategies to protect petrochemical infrastructure and nearby communities during storm surge. Natural Hazards Review, 19(4), 04018019. https://doi.org/10.1061/(ASCE)N H.1527-6996.0000309

Bolin, B. and Kurtz, L.C. (2018). Race, class, ethnicity, and disaster vulnerability. Handbook of Disaster Research. Springer International Publishing, pp 181-203. https://doi.org/10.1007/978-3-319-6 3254-4_10

Bodenreider, C., Wright, L., Barr, O., Xu, K. and Wilson, S. (2019). Assessment of social, economic, and geographic vulnerability preand post-Hurricane Harvey in Houston, Texas. Environmental Justice, 12(4), 182-193. https://doi.org/10.1089/env.2019.0001
Brody, S., Blessing, R., Sebastian, A. and Bedient, P. (2014). Examining the impact of land use/land cover characteristics on flood losses. Journal of Environmental Planning and Management, 57(8), 12521265. https://doi.org/10.1080/09640568.2013.802228

Bullard, R.D. (2005). The Quest for Environmental Justice: Human Rights and the Politics of Pollution. Sierra Club Books.

Bullard, R.D. (2007). Equity, unnatural man-made disasters, and race: Why environmental justice matters. Equity and the Environment. Emerald Group Publishing Limited, pp 51-85. https://doi.org/10.10 16/S0196-1152(07)15002-X

Carter, J.M. and Kalman, C. (2019). Future floods \& Superfund sites: toxic contamination risks in coastal communities. American Geophysical Union, Fall Meeting 2019. https://ui.adsabs.harvard.edu/a bs/2019AGUFMIN44B..07C/abstract (accessed May 7, 2021).

Chakraborty, J., Collins, T.W. and Grineski, S.E. (2019). Exploring the environmental justice implications of Hurricane Harvey flooding in Greater Houston, Texas. American Journal of Public Health, 109(2), 244-250. https://doi.org/10.2105/AJPH.2018.304846

Collins, M.B., Munoz, I. and JaJa, J. (2016). Linking 'toxic outliers' to environmental justice communities. Environmental Research Letters, 11(1), 015004. https://doi.org/10.1088/1748-9326/11/1/0150 04

Collins, T.W., Grineski, S.E., Chakraborty, J. and Flores, A.B. (2019). Environmental injustice and Hurricane Harvey: A household-level study of socially disparate flood exposures in Greater Houston, Texas, USA. Environmental Research, 179, 108772. https://doi.org/ 10.1016/j.envres.2019.108772

Cope, M.R. and Slack, T. (2017). Emplaced social vulnerability to technological disasters: Southeast Louisiana and the BP Deepwater Horizon oil spill. Population and Environment, 38(3), 217-241. https://doi.org/10.1007/s11111-016-0257-8

Flanagan, B.E., Hallisey, E.J., Adams, E. and Lavery, A. (2018). Measuring community vulnerability to natural and anthropogenic hazards: The Centers for Disease Control and Prevention's Social Vulnerability Index. Journal of Environmental Health, 80(10), 34-36.

Flores, A.B., Castor, A., Grineski, S.E., Collins, T.W. and Mullen, C. (2021). Petrochemical releases disproportionately affected socially 
vulnerable populations along the Texas Gulf Coast after Hurricane Harvey. Population and Environment, 42(3), 279-301. https://doi.o rg/10.1007/s11111-020-00362-6

Grineski, S., Collins, T.W., Chakraborty, J. and Montgomery, M. (2015). Hazardous air pollutants and flooding: A comparative interurban study of environmental injustice. GeoJournal, 80(1), 145158. https://doi.org/10.1007/s10708-014-9542-1

Johnston, J. and Cushing, L. (2020). Chemical exposures, health, and environmental justice in communities living on the fenceline of industry. Current Environmental Health Reports, 7(1), 48-57. https: //doi.org/10.1007/s40572-020-00263-8

Kanashiro, P. (2020). Can environmental governance lower toxic emissions? A panel study of US high-polluting industries. Business Strategy and the Environment, 29(4), 1634-1646. https://doi.org/10. 1002/bse. 2458

Lee, J., Newman, G., and Park, Y. (2018). A comparison of vacancy dynamics between growing and shrinking cities using the land transformation model. Sustainability, 10(5), 1513. https://doi.org $/ 10.3390 /$ su 10051513

Marcantonio, R.A., Field, S. and Regan, P.M. (2019). Toxic trajectories under future climate conditions. PLOS ONE, 14(12), e0226958. https://doi.org/10.1371/journal.pone.0226958

Molefi, M., Thakanelo, J., Phologolo, T., Hamda, S.G., Masupe, T., Tsima, B., Setlhare, V., Mashalla, Y. and Wiebe, D. (2020). The impact of China's lockdown policy on the incidence of CoVID-19: An Interrupted time series analysis. https://doi.org/10.21203/rs.3.rs329 $44 / \mathrm{v} 1$

Miller, M.M. and Shirzaei, M. (2019). Land subsidence in Houston correlated with flooding from Hurricane Harvey. Remote Sensing of Environment, 225, 368-378. https://doi.org/10.1016/j.rse.2019.03.0 22

Miller, M.M. and Shirzaei, M. (2021). Assessment of future flood hazards for southeastern Texas: Synthesizing subsidence, sea-level rise, and storm surge scenarios. Geophysical Research Letters, 48(8), e2021GL092544. https://doi.org/10.1029/2021GL092544

Newman, G., Shi, T.G., Yao, Z., Li, D.Y., Sansom, G., Kirsch, K., Casillas, G. and Horney, J. (2020). Citizen science-informed community master planning: Land use and built environment changes to increase flood resilience and decrease contaminant exposure. International Journal of Environmental Research and Public Health, 17 (2), 486. https://doi.org/10.3390/ijerph17020486

Newman, G., Malecha, M. and Atoba, K. (2021). Integrating ToxPi outputs with ArcGIS Dashboards to identify neighborhood threat levels of contaminant transferal during flood events. Journal of Spatial Science, 0(0), 1-13. https://doi.org/10.1080/14498596.2021.189 1149

Saha, S., Shekhar, S., Sadhukhan, S. and Das, P. (2018). An analytics dashboard visualization for flood decision support system. Journal of Visualization, 21(2), 295-307. https://doi.org/10.1007/s12650-01 7-0453-3 Carter,

Sengul, H., Santella, N., Steinberg, L.J. and Cruz, A.M. (2012). Analysis of hazardous material releases due to natural hazards in the United States. Disasters, 36(4), 723-743. https://doi.org/10.1111/j.1 467-7717.2012.01272.x

Stone, K.W., Casillas, G.A., Karaye, I., Camargo, K., McDonald, T.J. and Horney, J.A. (2019). Using spatial analysis to examine potential sources of polycyclic aromatic hydrocarbons in an environmental justice community after Hurricane Harvey. Environmental Justice, 12(4), 194-203. https://doi.org/10.1089/env.2019.0007

Summers, K., Lamper, A. and Buck, K. (2021). National hazards vulnerability and the remediation, restoration and revitalization of contaminated sites-1. Superfund. Environmental Management, 67(6), 1029-1042. https://doi.org/10.1007/s00267-021-01459-w

Psyllidis, A., Bozzon, A., Bocconi, S., and Bolivar, C.T. (2015). A platform for urban analytics and semantic data integration in city planning. In International Conference on Computer-Aided Architectural Design Futures. Springer, Berlin, Heidelberg.

Texas Commission on Environmental Quality (2017). Air Emission Event Re-port Database. https://www2.tceq.texas.gov/oce/eer/inde x.cfm?fuseaction=main.getDetails\&target $=26675$ (accessed April 20, 2021).

The Right To Know Network (2019). Risk Managment Plans (RMP). https://rtk.rjifuture.org/rmp/

U.S. EPA (2019). Release Chemical Report. https://enviro.epa.gov/trie xplorer/tri release.chemical (accessed April 25, 2021).

Whyte, J. (2019). The Morals of the Market: Human Rights and the Rise of Neoliberalism. Verso Books: London.

Wilson, R.P. (2014). Hurricane Sandy: Environmental impact and agency efforts. Environmental Claims Journal, 26(2), 126-156. https://doi. org/10.1080/10406026.2014.868741

Zachry, B.C., Booth, W.J., Rhome, J.R., and Sharon, T.M. (2015). A national view of storm surge risk and inundation. Weather, Climate, and Society, 7(2), 109-117. https://doi.org/10.1175/WCAS-D-1400049.1 